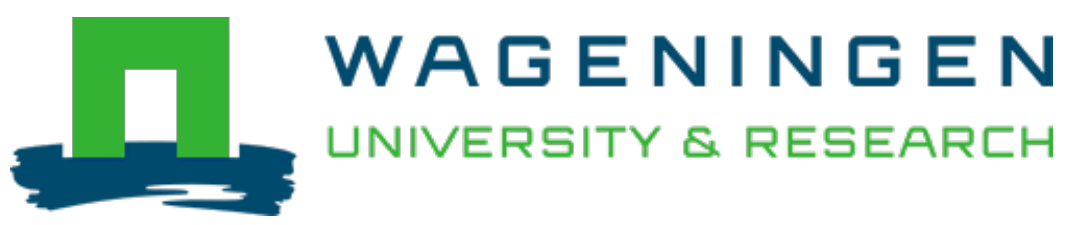

\title{
Understanding the effect of storage temperature on the quality of semi-skimmed UHT hydrolyzed-lactose milk : an insight on release of free amino acids, formation of volatiles organic compounds and browning
}

Food Research International

Bottiroli, Riccardo; Troise, Antonio Dario; Aprea, Eugenio; Fogliano, Vincenzo; Gasperi, Flavia et al https://doi.org/10.1016/j.foodres.2021.110120

This article is made publicly available in the institutional repository of Wageningen University and Research, under the terms of article $25 \mathrm{fa}$ of the Dutch Copyright Act, also known as the Amendment Taverne. This has been done with explicit consent by the author.

Article 25 fa states that the author of a short scientific work funded either wholly or partially by Dutch public funds is entitled to make that work publicly available for no consideration following a reasonable period of time after the work was first published, provided that clear reference is made to the source of the first publication of the work.

This publication is distributed under The Association of Universities in the Netherlands (VSNU) 'Article $25 \mathrm{fa}$ implementation' project. In this project research outputs of researchers employed by Dutch Universities that comply with the legal requirements of Article 25fa of the Dutch Copyright Act are distributed online and free of cost or other barriers in institutional repositories. Research outputs are distributed six months after their first online publication in the original published version and with proper attribution to the source of the original publication.

You are permitted to download and use the publication for personal purposes. All rights remain with the author(s) and / or copyright owner(s) of this work. Any use of the publication or parts of it other than authorised under article $25 \mathrm{fa}$ of the Dutch Copyright act is prohibited. Wageningen University \& Research and the author(s) of this publication shall not be held responsible or liable for any damages resulting from your (re)use of this publication.

For questions regarding the public availability of this article please contact openscience.library@wur.nl 


\title{
Understanding the effect of storage temperature on the quality of semi-skimmed UHT hydrolyzed-lactose milk: an insight on release of free amino acids, formation of volatiles organic compounds and browning
}

\author{
Riccardo Bottiroli $^{\mathrm{a}, \mathrm{b}}$, Antonio Dario Troise ${ }^{\mathrm{b}, \mathrm{c}}$, Eugenio Aprea ${ }^{\mathrm{a}, \mathrm{d}, *}$, Vincenzo Fogliano ${ }^{\mathrm{e}}$, \\ Flavia Gasperi $^{\text {a,d }}$, Paola Vitaglione ${ }^{\mathrm{b}}$ \\ ${ }^{a}$ Department of Food Quality and Nutrition, Research and Innovation Centre, Fondazione Edmund Mach, via E. Mach 1, 38010 San Michele all'Adige, TN, Italy \\ ${ }^{\mathrm{b}}$ Department of Agriculture and Food Science, University of Naples, Federico II, 80055 Portici, NA, Italy \\ c Proteomics \& Mass Spectrometry Laboratory, ISPAAM - CNR, 80055 Portici, NA, Italy \\ ${ }^{\mathrm{d}}$ Center Agriculture Food Environment, University of Trento/Fondazione Edmund Mach, via E. Mach 1, 38010 San Michele all'Adige, TN, Italy \\ ${ }^{\mathrm{e}}$ Food Quality \& Design Group, Wageningen University, PO Box 8129, 6700 EV Wageningen, the Netherlands
}

\section{A R T I C L E I N F O}

\section{Keywords:}

Hydrolyzed-lactose milk

Maillard reaction

Storage temperature

Shelf-life

\begin{abstract}
A B S T R A C T
Proteolytic side activity of the lactase preparations (LPs) intended for ultra-high temperature hydrolyzed-lactose milk (UHLM) production induces changes in the product quality during shelf-life. The problem is particularly relevant when the enzyme is added aseptically in the packaging ("in pack" process), while the negative quality effects can be mitigated following the "in batch" process adding the LP before thermal sterilization. In this study, we monitored the quality over time of UHLM produced "in batch" and stored at 4, 20, 30 and $40{ }^{\circ} \mathrm{C}$ focusing on proteolysis, volatiles organic compounds (VOCs) formation and color changes. The goal was to identify the key reactions and compounds relevant for the product quality. An increase in storage temperature determined significant changes in the free amino acids profile increasing Strecker aldehydes and methyl ketones formation. At 30 and $40{ }^{\circ} \mathrm{C}$, Maillard reaction and lipid oxidation ended up in a modification of the milk color, whereas at 4 and $20^{\circ} \mathrm{C}$ no significant alteration was observed. Altogether, the results suggested a coordinate involvement of Maillard reaction, protein and lipid oxidation to milk browning and off-flavors formation in UHLM.
\end{abstract}

\section{Introduction}

In the current market, the high demand of long-lasting dairy products with stable quality is satisfied by heat treatment (Sunds, Rauh, Sørensen, \& Larsen, 2018). In particular, ultra-high temperature (UHT) treatment extends the commercial shelf-life of the milk at room temperature up to 6-9 months, by exposing the product to elevate temperature for very short time (Zabbia, Buys, \& de Kock, 2012). This is accomplished by aseptic packaging, which maintains the product sterile throughout the shelf-life once the heat load inactivates the pathogens present in the milk (Valero, Villamiel, Miralles, Sanz, \& Martínez-Castro, 2001).
Europe is currently the largest market for regular UHT milk, with an estimate of 7 out of 10 people consuming the product regularly (Bimbo, Bonanno, Liu, \& Viscecchia, 2016). On the other hand, the milk market globalization and the price war started by food retailers is pushing European manufacturers to expand their product portfolio (Bimbo et al., 2016), rendering also the export an appealing opportunity to increase profit margins. In this context, launches of hydrolyzed-lactose milk (HLM) products rocketed in the recent past, riding the wave of the increasing awareness towards lactose intolerance (Nielsen et al., 2017). HLM has a lower shelf-life than regular UHT milk and this hampers the export in Asia, where lactose intolerance has high prevalence and the market is expanding.Fluid milk is the product category growing the most

\footnotetext{
Abbreviations: HRMS, high resolution mass spectrometry; HS-SPME GC-MS, headspace solid-phase microextraction gas chromatography mass spectrometry; LC, liquid chromatography; LP, lactase preparation; MR, Maillard reaction; MRP, Maillard reaction products; UHLM, Ultra-high-temperature lactose-free milk; UHT, Ultra-high-temperature; VOC, volatile organic compound.

* Corresponding author at: Fondazione Edmund Mach, Via E. Mach, 3010 San Michele a/A, Italy.

E-mail addresses: riccardo.bottiroli@fmach.it (R. Bottiroli), antoniodario.troise@cnr.it (A.D. Troise), eugenio.aprea@unitn.it (E. Aprea), vincenzo.fogliano@wur. nl (V. Fogliano), flavia.gasperi@unitn.it (F. Gasperi), paola.vitaglione@unina.it (P. Vitaglione).
} 
and UHT hydrolyzed-lactose milk (UHLM) leads the positive trend (Dekker, Koenders, \& Bruins, 2019).

Manufacturing of UHLM is challenging and operating conditions should be carefully monitored to maintain high quality standards (Bottiroli, Pedrotti, et al., 2020). In general, reactions occurring during UHT processing may alter the sensory profile (especially the flavor) of UHT milk, jeopardizing its acceptability (Jansson et al., 2019; Sunds et al., 2018). Maillard reaction (MR), lipid oxidation and protein denaturation, oxidation and hydrolysis are the key reactions and they tend to proceed faster in UHLM compared to regular UHT milk (Jansson et al., 2014, 2017; Messia, Candigliota, \& Marconi, 2007; Olli Tossavainen \& Kallioinen, 2008). The higher reactivity of glucose and galactose compared to lactose, as well as the proteolytic side activity of the commercial lactase preparations (LPs), promote MR resulting in products with a shorter commercial shelf-life of $90-120$ days at room temperature (Milkovska-Stamenova \& Hoffmann, 2017; Naranjo, Gonzales, Leiva, \& Malec, 2013; Nielsen et al., 2018). Chemical modifications influence physicochemical parameters of milk and in the case of lactosehydrolyzed milk, glycation alters protein structures and conformation, thus modifying also hydrophobicity and aggregation with consequences on viscosity and gel formation (Hannß, Hubbe, \& Henle, 2018).

The MR is triggered by the reaction between reducing sugars and protein. In UHLM, the proteolytic side activity of the commercial lactase enhances the release of free amino acids by increasing the substrate available for the propagation of MR (Jansson et al., 2014; Tossavainen \& Kallioinen, 2007; Troise et al., 2016). Besides browning and loss of nutritional value, flavor compounds are generated via MR (van Boekel, 2006) and are considered the major limiting factors affecting the sensory quality of both regular UHT milk and UHLM (Jansson et al., 2019; Sunds et al., 2018).

The development of UHLM with sensory characteristics resembling to regular UHT milk is a major priority for dairy manufactures, but a limited number of research articles have been published on the topic (Adhikari, Dooley, Chambers IV, \& Bhumiratana, 2010; Jensen et al., 2015; Nielsen et al., 2017; Troise et al., 2016). In order to be appreciated by consumers, milk should provide a refreshing mouthfeel without any odors and aftertaste (Francis et al., 2005). Sensory properties of UHLM tend to differ from regular UHT milk in terms of a sweetness, cooked flavor, processed flavor and chalkiness, all more intense in the former (Adhikari et al., 2010). Jensen et al. (2015) studied the off-flavors formation in UHLM during storage in relation to the sensory profile and reported that the formation of specific volatiles organic compounds (VOCs) following Maillard pathways underpins the development of stale flavor. An increase in the concentration of methyl ketones, aldehydes and organic acids during storage appeared as major responsible for the development of this sensory defect in UHLM (Bottiroli, Troise, et al., 2020; Jensen et al., 2015). Our group estimated these VOCs in UHLM both by HS SPME GC-MS and PTR-TOF-MS, outlining that off-flavors are created mostly alongside Strecker degradation (Bottiroli, Aprea, Betta, Fogliano, \& Gasperi, 2020; Bottiroli, Pedrotti, et al., 2020).

Along with the availability and chemical nature of the substrate, temperature, time, $\mathrm{pH}$ and water content are other key factors that supervise the formation of VOCs via MR (van Boekel, 2006). The propagation of the MR towards advanced stages is modulated by the storage time and temperature which, if not properly controlled, can lead to changes in color, nutritional value and flavor of the milk (van Boekel, 1998). Therefore, understanding the influence of the storage conditions on milk aging is necessary to develop strategies aimed to extend the shelf-life of UHLM, minimizing sensory defects. The aim of this study was to investigate the effect of different storage temperatures $(4,20,30$ and $40{ }^{\circ} \mathrm{C}$ ) on chemical modifications of UHLM considering the proteolysis, the VOCs evolution and the color development, focusing on parameters linked to MR and product quality.

\section{Material and methods}

\subsection{Chemical reagents}

Acetonitrile and water were purchased from Merck (Darmstadt, Germany). Formic acid, the analytical standards $\left[4,4,5,5-d_{4}\right]-\mathrm{L}-1 y s i n e$ hydrochloride ( $d_{4}$-lysine), L-lysine- $6-{ }^{13} \mathrm{C}$ dihydrochloride $\left({ }^{13} \mathrm{C}\right.$-lysine), the 20 L-amino acids analytical standards for the LC-HMRS and the 4methyl-2-pentanone (purity $\geq 99 \%$ ) for the GC-MS analysis were obtained from Sigma-Aldrich (St. Louis, MO).

\subsection{UHT hydrolyzed-lactose milk samples}

Milk was manufactured at industrial scale following the "in batch" production system as described in a previous work (Bottiroli, Troise, et al., 2020). The "in batch" UHLM is produced by adding the LP intended for lactose hydrolysis in a tank before UHT sterilization. In this way, the desired level of lactose hydrolysis is achieved before bottling and the LP remains inactivated throughout the product shelf-life.

The starting milk was semi-skimmed and its proximate composition is reported in Supplementary Table A.1. Production was performed at industrial scale and it was repeated three times, on three consecutive weeks, taking into account the batch variability.

Lactose conversion was performed at refrigerated conditions until a final lactose concentration of $<0.1 \mathrm{~g} / \mathrm{L}$ was obtained. Residual lactose content was monitored according to Troise et al. (2016). The commercial LP used for production was extracted from Kluyveromyces lactis and had an enzymatic activity higher than $5000 \mathrm{NUL} / \mathrm{g}$. Direct UHT treatment was then applied and the obtained UHLM were packed aseptically (1L bottle). After production, UHLM bottles were stored in different climate chambers at the following temperatures: $4{ }^{\circ} \mathrm{C}, 20{ }^{\circ} \mathrm{C}, 30{ }^{\circ} \mathrm{C}$, $40^{\circ} \mathrm{C}$. Sampling started after 30 days of storage and was carried on until 120 days, based on the best-before date of each milk package. UHLM samples were collected every 30 days and kept at $-80^{\circ} \mathrm{C}$ until analyses.

\subsection{Liquid chromatography-high-resolution mass spectrometry (LC- HRMS)}

Free amino acids were analyzed according to the procedure previously reported by our group (Troise, Wiltafsky, Fogliano, \& Vitaglione, 2018). Briefly, $0.1 \mathrm{~mL}$ of acetonitrile were added to milk samples (0.1 $\mathrm{mL}$ ), then spiked with $d_{4}$-lysine; after protein precipitation, samples were centrifuged at $4{ }^{\circ} \mathrm{C}$, for $15 \mathrm{~min}$ at $21,100 \mathrm{~g}$. Samples were diluted ten times in a mixture of acetonitrile and water 50:50 and filtered by using cellulose filters (RC, $0.22 \mu \mathrm{m}$ Sartorius, Gottingen, Germany). Chromatographic separation of amino acids was achieved at $30{ }^{\circ} \mathrm{C}$ by using a Syncronys HILIC $(3.0 \mu \mathrm{m}, 50 \times 2.1 \mathrm{~mm}$, Thermo Fisher, Bremen, Germany). Mobile phases were $0.1 \%$ formic acid in acetonitrile (solvent A), $0.1 \%$ formic acid in water (solvent B) and the following linear gradient of solvent B (min/\%B): (0/5), (1.50/5), (8/90), (10/90) was used, the flow rate was set to $300 \mu \mathrm{L} / \mathrm{min}$ and the injection volume was $5 \mu \mathrm{L}$. The Accela 1250 U-HPLC system (Thermo Fisher Scientific, Bremen, Germany) was interfaced to an Exactive Orbitrap HRMS (Thermo Fisher Scientific, Bremen, Germany) and the analytes were detected through a heated electrospray interface (HESI-II) operating in positive mode. Interface parameters and analytical performances were set and evaluated according to a previous work (Bottiroli, Troise, et al., 2020). Samples were spiked with ${ }^{13} \mathrm{C}$-lysine before each injection and its exact mass $\left([\mathrm{M}+\mathrm{H}]^{+}, 148.11616\right)$ was used as a reference to maximize response and to check instrumental resolution and performance.

\subsection{Headspace solid-phase micro-extraction gas chromatography mass spectrometry (HS SPME GC-MS)}

The HS-SPME GC-MS analysis was conducted according to a previous research article (Bottiroli, Aprea, et al., 2020). For each UHLM 
sample, $5 \mathrm{~mL}$ were collected in $20 \mathrm{~mL}$ vials (Supelco, Bellefonte, PA). 4Methyl-2-pentanone was added as internal standard (IS). A 2 cm DVBCarboxen-PDMS SPME fiber heated at $40{ }^{\circ} \mathrm{C}$ for $60 \mathrm{~min}$ was used for the VOCs collection. VOCs were desorbed in the injector port of a GC Clarus 500 (PerkinElmer, Norwalk, CT) at $250{ }^{\circ} \mathrm{C}$. The GC was interfaced with a mass detector operating in an electron ionization mode (internal ionization source: $70 \mathrm{eV}$; scan range: $m / z 33-300)$. Measurements were operated in automatic by an auto-sampler (CTC combiPAL, CTC Analysis AG, Zwingen, Switzerland). The separation of the injected mix of VOCs was obtained using a HP-Innowax fused-silica capillary column (Agilent Technologies, Palo Alto, CA) having the following characteristics: $30 \mathrm{~m}$ length, $0.32 \mathrm{~mm}$ inner diameter, $0.5 \mu \mathrm{m}$ film thickness. The oven temperature was set with different consecutive steps, namely $40{ }^{\circ} \mathrm{C}$ for 3 $\min , 180{ }^{\circ} \mathrm{C}$ for $6 \mathrm{~min}$ at $4{ }^{\circ} \mathrm{C} \mathrm{min}^{-1}$ and $220^{\circ} \mathrm{C}$ for $3 \mathrm{~min}$ at $3^{\circ} \mathrm{C} \mathrm{min}^{-1}$. Helium was used as gas carrier (flow rate set at $2 \mathrm{~mL} / \mathrm{min}$ ). Compounds extracted from the UHLM headspace were identified using the mass spectra matching the NIST-2014/Wiley 7.0 libraries and comparing the calculated LRI with those available from literature. Semi-quantitative data were calculated as $\mu \mathrm{g} / \mathrm{L}$ of internal standard 4-methyl-2-pentanone.

\subsection{Color analysis}

The color was measured with a CM-3500d (Minolta, Japan). The instrument was calibrated with distilled water and the opaque material provided by the manufacturer. Samples were measured at room temperature using a quartz cell with $1 \mathrm{~cm}$ of optical path. Results were expressed using the CIELAB color system with L* (lightness; range: $0-100,0=$ black and $100=$ white $), a^{*}\left(-a^{*}\right.$ : green color; $+a^{*}$ red color $)$, and $b *$ ( $-b^{*}$ blue color; $+b^{*}$ yellow color). Results were averaged on three readings taken on each UHLM sample.

\subsection{Statistical data analysis}

All the statistical analyses were performed using RStudio (RStudio Team 2018. RStudio: Integrated Development for R. RStudio, Inc., Boston, MA) and STATISTICA 13.3 (StatSoft, Inc., Tulsa, OK). Patterns in the free amino acids profile were explored by Principal Component Analysis (PCA) performing a log-transformation and a scaling to unit variance on all the variables prior to the analysis. The effect of the storage time and temperature on each detected free amino acids, VOCs and color parameter was further investigated by the analysis of variance and Tukey post-hoc test. A confidence interval $(P \leq 0.05)$ was chosen as threshold for significance. The relationships among the three datasets, that we considered an approximation of the three different stages of MR (initial: free amino acids profile by LC-HRMS; intermediate: VOCs profile by GC-MS; final: color by CIELab system) were studied by Multiple Factorial Analysis (MFA). These three datasets were considered active data, whereas storage time and temperature were included in the model as supplementary. To further support the relationships pointed out by the multivariate analysis, Pearson regression coefficients ( $r$ ) were calculated for direct paired comparison of the variables.

\section{Results and discussion}

\subsection{Free amino acids profile and initial stages of Maillard reaction}

The concentration of free amino acids in the UHLMs stored at different temperatures ranged from 0.154 to $33.304 \mu \mathrm{g} / \mathrm{mL}$. Acidic (glutamic acid, aspartic acid) and aliphatic (alanine, valine, isoleucine/ leucine) amino acids were the two classes of amino acids exhibiting the highest levels in their free form during the shelf-life. The highest median value was observed for acidic amino acids due to the huge contribution of free glutamic acid, which was by far the amino acid present in the highest amounts (concentration range: 8.016-33.304 $\mu \mathrm{g} / \mathrm{mL}$ ). Among the aliphatic amino acids, comparable levels of alanine (concentration range: $2.185-4.884 \mu \mathrm{g} / \mathrm{mL}$ ) and isoleucine/leucine (concentration range: $1.895-3.707 \mu \mathrm{g} / \mathrm{mL})$ were encountered, whereas valine registered higher values (concentration range: $2.965-8.581 \mu \mathrm{g} / \mathrm{mL}$ ).

An explorative snapshot of the influence of the two independent factors on the free amino acids content was obtained through Principal Component Analysis (PCA), whose score and loading plots are reported in Fig. 1. The first two scores of the UHLM samples showed a spatial distribution of the tested milk depending on the applied storage temperature. The factor appeared more important for distinguishing the free amino acids profiles of UHLMs compared to the storage time, that did not show any particular trend. All samples stored at $4{ }^{\circ} \mathrm{C}(30-120$ days) were discriminated based on their free amino acids profiles from the milk stored at the higher temperatures. According to the loadings, an overall higher concentration of free amino acids was responsible for the separation from the rest of the samples.

From the bi-plot, a higher concentration of free hydroxyproline, histidine and glutamic acid characterized the UHLMs stored at temperature higher than conventional $20^{\circ} \mathrm{C}$. From the time course evolution of the free amino acids (Supplementary Fig. A.1), a change in the trends of these three amino acids can be observed: from being relatively constant over time when milk was stored at $4{ }^{\circ} \mathrm{C}$ and $20^{\circ} \mathrm{C}$, the three amino acids shifted towards an upward trend when the storage temperature was increased. This pattern was particularly remarkable at $30{ }^{\circ} \mathrm{C}$.

The occurrence of free hydroxyproline in the milk is determined by free proline hydroxylation, but the reaction kinetics at the tested temperatures are unknown (Abernethy \& Higgs, 2013). The trend of free glutamic acid instead may confirm the specificity of the proteolytic side activity of the LP towards specific amino residues as well as a positive correlation with the temperature. In a previous work, we showed that the type of amino acids released during "in batch" production does not depend only on the degree of lactase purity, but also on the specificity of the proteolytic activity, as different free amino acids profiles were obtained in UHLMs treated with different lactases (Bottiroli, Troise, et al., 2020). In particular, UHLM produced with the same lactase used in this study caused a significant release of glutamic acid in milk. Although in this case glutamic acid was the only amino acid showing this behavior, the result may indicate that, at storage temperature higher than $20^{\circ} \mathrm{C}$, release of free amino acids can still occur in the milk. Previous data taken at $20^{\circ} \mathrm{C}$ are on the other hand not in agreement (Bottiroli, Troise, et al., 2020). The fact that glutamic acid is not converted through Strecker degradation may explain also the opposite trend showed at $40{ }^{\circ} \mathrm{C}$ by those amino acids involved in the reaction (e.g. isoleucine/ leucine, methionine, phenylalanine). At the same time, we cannot exclude that also other types of enzymes (e.g. heat stable proteases deriving from the raw milk) did not contribute to the pattern.

The 2-ways ANOVA $(P \leq 0.05)$ tested the effects of storage temperature and time on the free amino acids profile of each milk batch and further demonstrated the trend shown in the PCA. A significant effect of the storage time was highlighted only for phenylalanine, tyrosine, lysine and glutamic acid: UHLM was poorly affected by temporal changes in the free amino acid profile. These findings add valuable information to the chemical nature of the modification occurring in UHLM produced by "in batch" system (Bottiroli, Troise, et al., 2020).

UHLM undergoes proteolysis that, releasing free amino groups, increases the MR rate (Jansson et al., 2017). This drawback is minimized during "in batch" production because the UHT treatment inactivates the secondary proteases of the LP. On the other hand, free amino acids accumulate during the "in batch" hydrolysis raising the formation of volatile glycation compounds during the shelf-life at room temperature (Bottiroli, Troise, et al., 2020). In this study, this reservoir of free amino acids generated during "in batch" production was converted at higher rates when the milk was stored at temperature higher than $4{ }^{\circ} \mathrm{C}$. Therefore, fluctuations of the temperature during warehousing, shipment and commercialization can trigger directly MR, as a lag-phase of proteolysis does not occur, so quality defects linked to unwanted color and flavor can occur in a relative short time forcing to reduce the best 


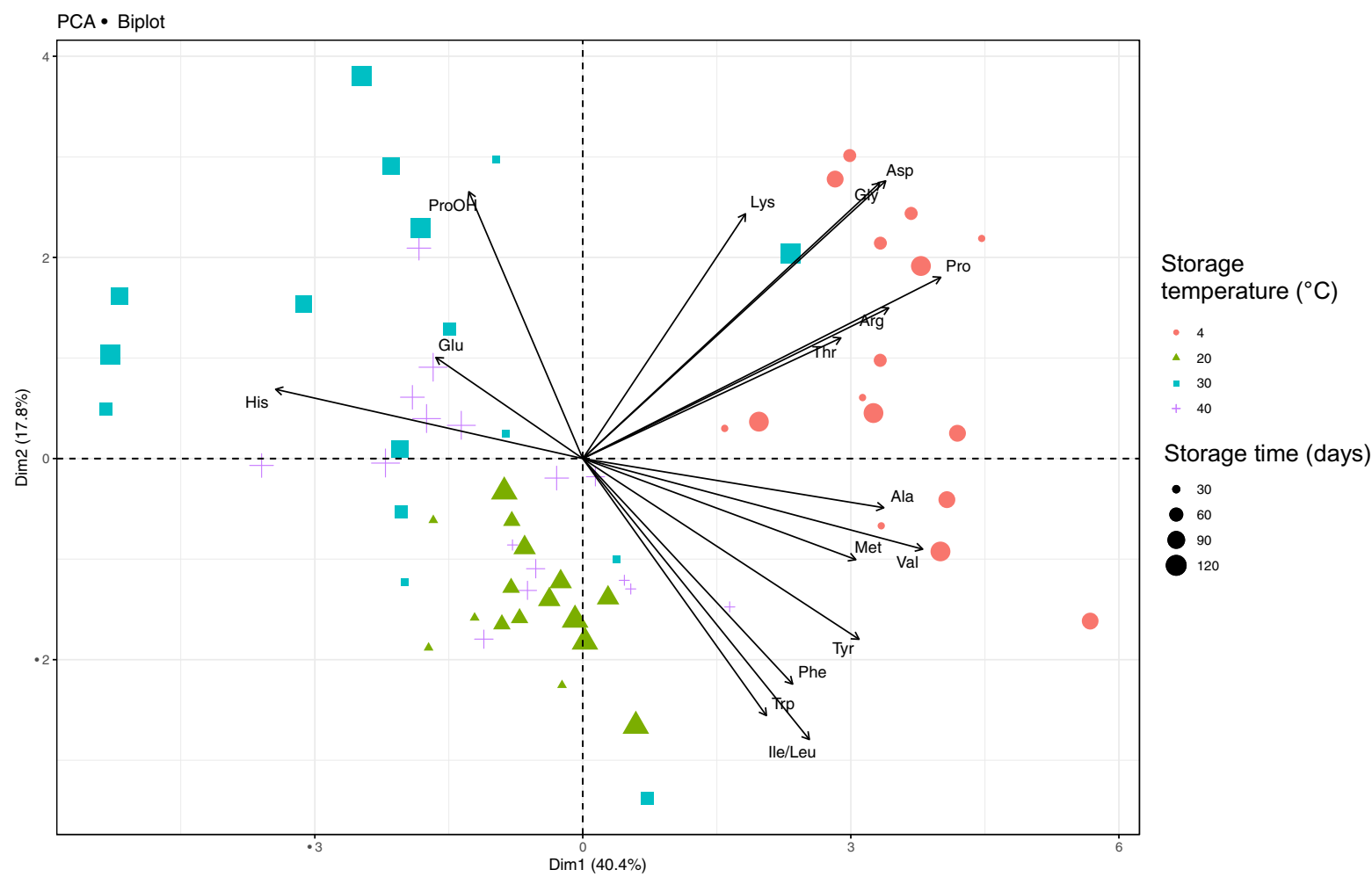

Fig. 1. Principal Component Analysis (PCA) bi-plot of the first (PC1; 40.4\% of the total variance) and the second (PC2; 17.8\% of the total variance) principal components performed on the free amino acids data of the UHLMs stored at different temperatures (the 4 related series are represented by different symbols and colors) for 120 days. Storage time (30-120 days, sampling every 30 days) is represented by an increasing size of the points. Black arrows indicated the corresponding weights of the loadings on the spatial distribution of the UHLM samples. Prior to analysis, data were log-transformed and scaled to unit variance, whereas outliers were removed.

Table 1

Overview of the volatile compounds (VOCs), calculated linear retention index (LRI) and reference linear retention index (RLRI) considered in the study by SPME GC-MS. The concentration range for each storage temperature is also reported. The complete VOCs profile of the analyzed UHLMs, with the concentrations expressed as $\mu \mathrm{g} / \mathrm{L}$ of internal standard (4-methyl-2-pentanone) for each VOCs, is reported in the Supplementary section of the manuscript.

\begin{tabular}{|c|c|c|c|c|c|c|}
\hline Compound name ${ }^{a}$ & LRI $^{\mathrm{b}}$ & $\mathrm{RLRI}^{\mathrm{c}}$ & $4^{\circ} \mathrm{C}^{\mathrm{d}}$ & $20^{\circ} \mathrm{C}$ & $30^{\circ} \mathrm{C}$ & $40^{\circ} \mathrm{C}$ \\
\hline 2-Butanone & 909 & $907 \pm 11$ & $2.89-7.54$ & $3.37-5.73$ & $3.88-6.87$ & $4.76-12.10$ \\
\hline 2-Methylbutanal & 918 & $914 \pm 8$ & $0.28-1.01$ & $0.63-1.78$ & $0.65-3.01$ & $1.53-18.18$ \\
\hline 2-Pentanone & 985 & $981 \pm 11$ & $3.24-8.01$ & $4.52-8.03$ & $6.19-15.70$ & $12.45-42.88$ \\
\hline Toluene & 1051 & $1042 \pm 11$ & $0.45-4.89$ & $0.57-1.59$ & $0.50-2.06$ & $0.29-1.00$ \\
\hline Dimethyl disulfide & 1099 & $1083 \pm 8$ & $0.11-0.51$ & $0.40-0.90$ & $0.24-1.05$ & $0.43-6.15$ \\
\hline Hexanal & 1137 & $1129 \pm 8$ & $3.04-11.8$ & $7.52-14.25$ & $3.59-13.63$ & $3.43-13.51$ \\
\hline 2-Heptanone & 1191 & $1182 \pm 8$ & $8.63-29.03$ & $8.70-27.00$ & $17.95-56.07$ & $27.50-105.53$ \\
\hline 2-Nonanone & 1395 & $1390 \pm 7$ & $2.79-6.52$ & $3.12-5.83$ & $5.48-29.00$ & $1.010-65.56$ \\
\hline Nonanal & 1400 & $1391 \pm 8$ & $0.35-2.23$ & nd -1.66 & $1.11-3.23$ & $1.81-7.30$ \\
\hline Furfural & 1476 & $1461 \pm 11$ & nd & nd & nd & $0.00-2.48$ \\
\hline Benzaldehyde & 1531 & $1520 \pm 14$ & $1.11-3.09$ & $0.84-2.68$ & $2.83-15.24$ & $4.66-31.82$ \\
\hline 1-Octanol & 1576 & $1557 \pm 8$ & $1.08-5.05$ & $1.21-1.83$ & $1.16-4.02$ & $0.92-7.95$ \\
\hline 2-Undecanone & 1605 & $1598 \pm 6$ & $0.73-1.96$ & $0.63-0.92$ & $1.51-8.29$ & $3.11-13.05$ \\
\hline Butyrolactone & 1636 & $1632 \pm 15$ & $0.58-1.25$ & $0.29-0.70$ & $0.57-2.44$ & $0.75-1.89$ \\
\hline Aceto-phenone & 1660 & $1647 \pm 13$ & nd -0.37 & nd -0.84 & $0.26-1.57$ & $0.31-0.87$ \\
\hline 2-Tridecanone & 1818 & $1809 \pm 6$ & $0.21-0.76$ & $0.06-0.47$ & $0.30-2.11$ & $0.6-3.10$ \\
\hline Dimethyl sulfone & 1890 & $1846 \pm 12$ & $1.80-6.43$ & $1.48-2.87$ & $0.97-6.47$ & $1.24-8.85$ \\
\hline Hexanoic acid & 1909 & $1903 \pm 9$ & $2.05-8.48$ & $1.44-4.36$ & $1.45-9.87$ & $2.92-46.07$ \\
\hline p-Cresol & 2095 & $2080 \pm 12$ & $0.15-0.44$ & $0.22-0.37$ & $0.21-1.86$ & $0.25-0.88$ \\
\hline m-Cresol & 2103 & $2091 \pm 18$ & $0.63-1.71$ & $0.87-1.30$ & $0.77-6.45$ & $0.94-3.52$ \\
\hline Octanoic acid & 2104 & $2060 \pm 15$ & $2.25-9.63$ & $2.70-4.88$ & $1.77-15.86$ & $3.93-31.21$ \\
\hline Delta-decalactone & 2198 & $2194 \pm 15$ & $0.30-0.81$ & nd -0.46 & nd -0.38 & $\mathrm{nd}-0.40$ \\
\hline Decanoic acid & 2295 & $2267 \pm 14$ & $2.95-8.34$ & $3.27-9.98$ & $3.37-24.50$ & $4.59-26.05$ \\
\hline
\end{tabular}

${ }^{\text {a }}$ Compound identification by match with the NIST-2014/Wiley 7.0 libraries.

b Calculated Linear Retention Index.

c Reference Linear Retention Index reported in the NIST-2014 library.

d Concentration range ( $\mu \mathrm{g} / \mathrm{L}$ of internal standard) detected for each storage temperature during the UHLM shelf-life (120 days with sampling every 30 days). 
before consumption date.

\subsection{Volatiles compounds and intermediate stages of Maillard reaction}

A total of 24 compounds were identified in the headspace of the samples, in line with other VOCs profiles reported for UHLM (Bottiroli, Aprea, et al., 2020; Troise et al., 2016); because of the high temperature used for milk storage $\left(40^{\circ} \mathrm{C}\right)$, the chromatographic profile was characterized by the presence of new peaks, such as furfural, a compound having a furan ring unit. A summary of the identified VOCs is given in Table 1, whereas the complete VOCs profile of the analyzed UHLMs is reported in the Supplementary section (Supplementary Table B.1-2). Furfural concentration increased linearly over the storage at $40{ }^{\circ} \mathrm{C}$, whereas it was not detected in the milk stored at the other temperature (Fig. 2d).

Furfural was previously detected in UHLM by Jansson et al. (2014) who hypothesized that its release is favored at $\mathrm{pH}<7$ alongside Amadori or 3-deoxyglucosone compounds formation (O'Mahony, Drapala, Mulcahy, \& Mulvihill, 2017).

Furfural formation is associated with the severity of the heat treatment supplied during milk sterilization. Previous research proved that, by increasing storage temperature, furfural is formed in parallel with formic and acetic acids along MR; as a consequence, the $\mathrm{pH}$ of the product tends to decrease during storage (Brands \& Van Boekel, 2001; van Boekel, 1998). Therefore, based on this assumption, our results indicate a positive correlation of high storage temperature and furfural formation, so milk sterilization should not be considered the major cause of furfural formation when the UHLM is stored at temperatures higher than the conventional $20^{\circ} \mathrm{C}$, but it promotes the formation/accumulation of triggering agents that boost the reaction when milk is stored at $40{ }^{\circ} \mathrm{C}$.

Along with furfural, Strecker aldehydes were detected in the UHLM samples. Strecker degradation is considered as the major contributor to the development of stale off-flavor in UHLM (Nielsen et al., 2017). Specifically, 2-methylbutanal increased significantly at $20^{\circ} \mathrm{C}, 30^{\circ} \mathrm{C}$ and $40{ }^{\circ} \mathrm{C}$, whereas dimethyl disulfide and benzaldehyde did at $30^{\circ} \mathrm{C}$ and $40{ }^{\circ} \mathrm{C}$ (Fig. 2a-c). In all the mentioned cases, the compounds followed a linear growth, and $40{ }^{\circ} \mathrm{C}$ was the temperature most sensitive to Strecker degradation, which takes place when amino acids react with $\alpha$-dicarbonyl compounds (Hofmann \& Schieberle, 2000). Alternatively, before $\alpha$-dicarbonyls formation, Amadori products (APs) can also react forming Strecker aldehydes through oxidative deamination and the consequent decarboxylation of the amino acids (Cremer, Vollenbroeker, \& Eichner, 2000). Products of Strecker degradation accumulate faster in UHLM than conventional UHT milk, due to the proteolytic activity of lactases employed for UHLM manufacturing, which are sold in different purities (Jansson et al., 2014; Nielsen et al., 2018).

The pool of free amino acids previously mentioned upon "in batch" production provides the substrate for Strecker degradation (Bottiroli, Troise, et al., 2020). The trends of 2-methylbutanal, dimethyl disulfide and benzaldehyde demonstrated that, at storage temperature of $30{ }^{\circ} \mathrm{C}$ and $40{ }^{\circ} \mathrm{C}$, intermediate stages of MR are facilitated. Indeed, at these
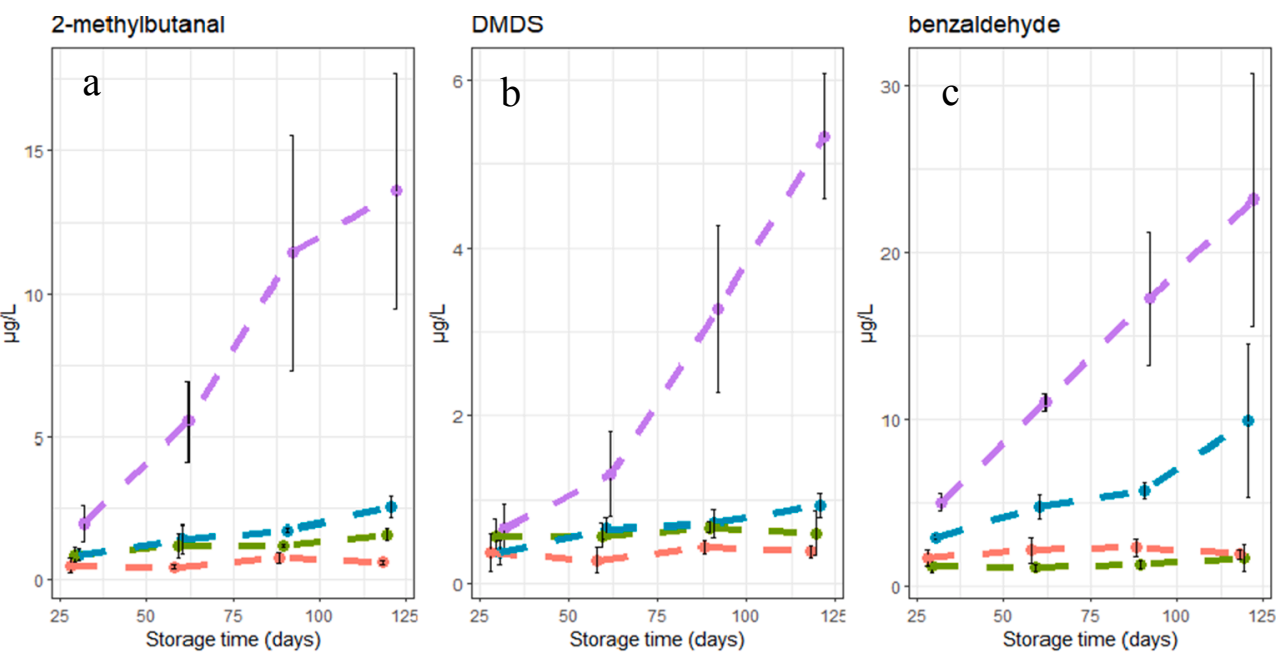

Storage temperature
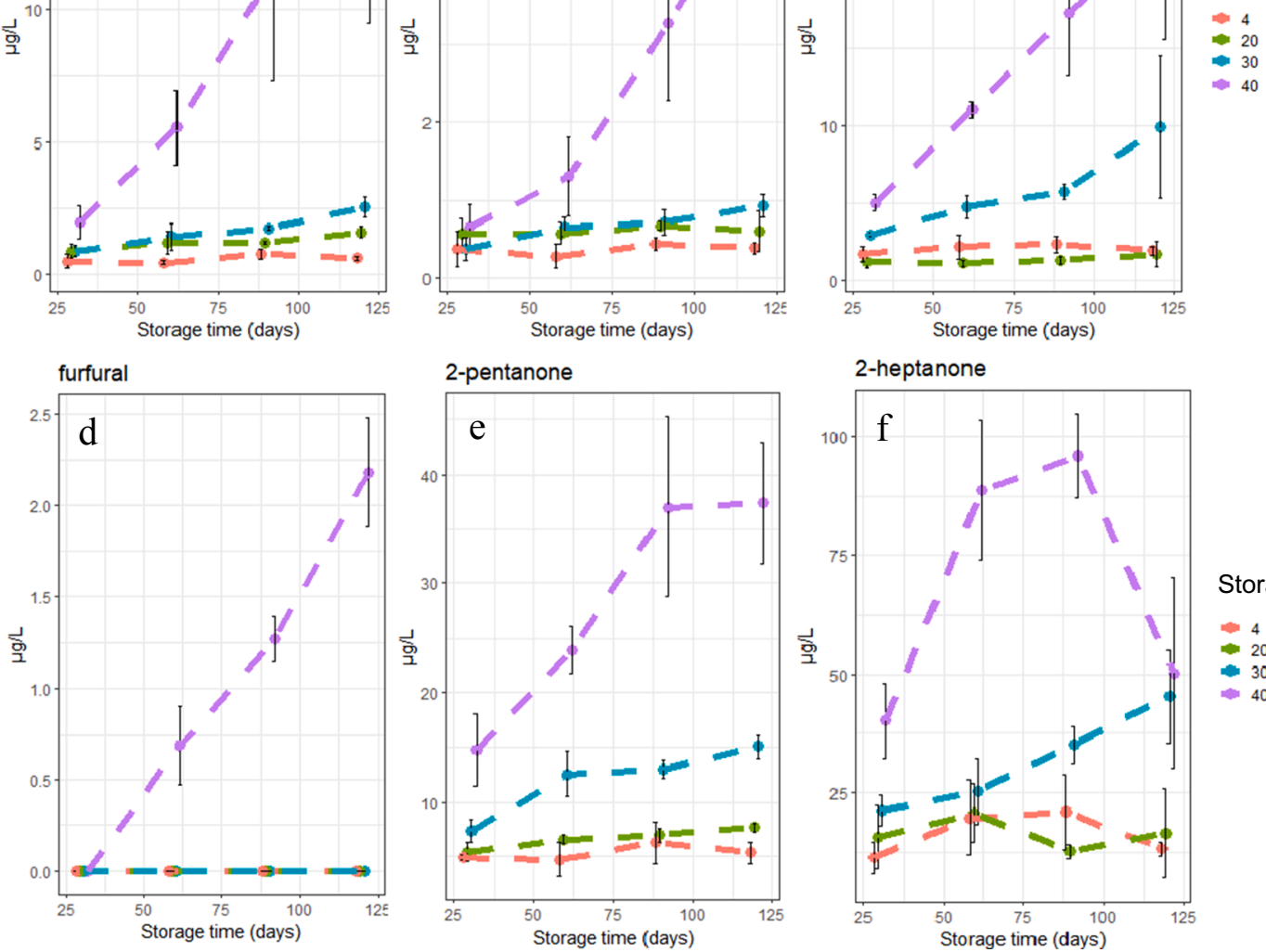

Storage temperature

4

$-20$

$=40$

Fig. 2. Concentration of 2-methylbutanal (a), dimethyl disulfide (b), benzaldehyde (c), furfural (d), 2-pentanone (e), 2-heptanone (f) detected the UHLMs stored at different temperatures $\left(4^{\circ} \mathrm{C}, 20^{\circ} \mathrm{C}, 30^{\circ} \mathrm{C}, 40{ }^{\circ} \mathrm{C}\right)$ for 120 days. The data are the mean values of the three replicates of production (n $=3$ ). 
temperatures, the reactivity of the free amino acids is higher and their conversion via Strecker degradation faster, explaining the progressive lower levels of free amino acids released when the storage temperature was higher than $4^{\circ} \mathrm{C}$.

Thermally-induced oxidation of lipids is also relevant when dealing with milk aging and can be estimated through the concentration of methyl ketones in the headspace. During "in batch" production, methylketones are significantly formed when the milk undergoes thermal sterilization after lactose hydrolysis (Bottiroli, Aprea, et al., 2020). In this study, methyl ketones were the most frequent class of VOCs detected, in accordance with previous data on UHT milk (Contarini \& Povolo, 2002; Contarini, Povolo, Leardi, \& Toppino, 1997; Vazquez-Landaverde, Velazquez, Torres, \& Qian, 2005). The higher incidence of even-carbonnumbered fatty acids in milk justifies the detection of methyl ketones having an odd number of carbons (Perkins, Elliott, D'Arcy, \& Deeth, 2005). The level of methyl ketones in UHLM increased as both storage time and temperature increased, confirming the temperature dependence of their formation: 2-pentanone and 2-heptanone were the most abundant VOCs, reaching maximum values of $37.4 \pm 5.58 \mu \mathrm{g} / \mathrm{L}$ and $95.99 \pm 8.85 \mu \mathrm{g} / \mathrm{L}$ respectively in the milks stored at $30{ }^{\circ} \mathrm{C}$ and $40{ }^{\circ} \mathrm{C}$ (Fig. 2e-f). Already after 30 days at $40{ }^{\circ} \mathrm{C}$, their concentration was significantly higher than the maximum reached at all the other storage temperatures $(P \leq 0.05)$. The trend of 2 -heptanone was particularly interesting: after 90 days at $40{ }^{\circ} \mathrm{C}$, its concentration dropped to values close to the ones registered in UHLM at end of the shelf-life at $30{ }^{\circ} \mathrm{C}$. Lipid oxidation and its interplay with MR and/or protein oxidation are other routes influencing UHLM sensory quality (Jensen et al., 2015). Methyl ketones are also positively correlated to molecules (e.g. protein bound lysine Amadori compounds and lactulose) describing heat milk damaging, and therefore, they can be considered an alternative way for evaluating the quality status of heated milk (Perkins et al., 2005). Both Strecker aldehydes and methyl ketones exhibited the same trend: the temperature step between $30^{\circ} \mathrm{C}$ and $40{ }^{\circ} \mathrm{C}$ was crucial for their formation and an acceleration of the reaction kinetics can be hypothesized.

\subsection{Color changes and final stages of Maillard reaction}

Changes in milk color occurs at the end of MR, when melanoidins and other colored pigments with a molecular weight below $500 \mathrm{~g} / \mathrm{mol}$ are formed (Rizzi, 1997; van Boekel, 1998). Color measurements is a valid rapid alternative for approximating the color of UHT milk in relation to the formation of melanonids and other colored compounds (Sunds et al., 2018). The results are reported in Fig. 3. Significant changes in $\mathrm{L}^{*}, \mathrm{a}^{*}, \mathrm{~b}$ * during storage were registered only when milk was stored at $30^{\circ} \mathrm{C}$ and $40^{\circ} \mathrm{C}$, suggesting that milk browning does not occur substantially at $4{ }^{\circ} \mathrm{C}$ and $20^{\circ} \mathrm{C}$ during the 120 -days storage considered in this study. Above $30{ }^{\circ} \mathrm{C}$ differences in color were already evident after 30 days, whereas at lower temperature the color was basically unaltered. This confirmed the heat load subjected to the milk during storage as major factor affecting milk browning, in a more relevant manner than the severity of UHT treatment itself (Deeth \& Lewis, 2017).

The parameter $L^{*}$ and $b^{*}$ significantly dropped by increasing the storage temperature, whereas the opposite was observed for the parameter $\mathrm{a}^{*}$. Interestingly, at $40{ }^{\circ} \mathrm{C}$ the temporal evolution of $\mathrm{L}^{*}, \mathrm{a}^{*}$ and $\mathrm{b}^{*}$ experienced a slowdown after 60 days of storage. Such change in time and temperature profiles was particularly evident for the parameter $\mathrm{a}^{*}$. This indicates that, at high storage temperature, formation of colored pigments may reach a plateau in milk. This means that MR decelerates because, at a certain point, glycation compounds are not converted to colored pigments and melanoidins anymore. The finding is in contrast with what reported by Sunds et al. (2018) for regular UHT milk but appears reasonable in UHLM due to the higher reactivity of glucose and galactose toward non-enzymatic browning (Milkovska-Stamenova \& Hoffmann, 2017).

\subsection{Comprehensive effect of different storage temperatures to UHT hydrolyzed-lactose milk quality}

The effect of storage time and temperature on the parameters defining the UHLM quality were the result of the interplay among MR, protein and lipid oxidation. Interrelated pathways can contribute to the formation of several molecules, denoting that an estimation of MRPs through free amino acids, VOCs linked to Strecker degradation and color changes was not sufficient. MR kinetics is intricate and several interconnected pathways can simultaneously occur (Deeth \& Lewis, 2017). Indeed, at certain conditions, Strecker aldehydes can condensate with carbonyl compounds, with sugar fragments and with furfurals, forming brown pigments and affecting the color as well (Morales \& Van Boekel, 1998). Intermediates from lipid oxidation can also participate to MR resulting in polymerization and contribution to non-enzymatic browning (Zamora \& Hidalgo, 2005). This inter-correlation between MR and lipid oxidation might explain the downtrend of 2-heptanone, in relation to the levelling-off of the a* colorimetric parameter after 90 days of storage in the UHLM maintained at $40^{\circ} \mathrm{C}$. This is a clear situation where methyl-ketones participated to MR and to milk browning.

In this scenario, where relationships among different sets of variables are proposed, multiple factor analysis (MFA) is a valuable tool for data discussion. It is important to highlight that the systematization of the
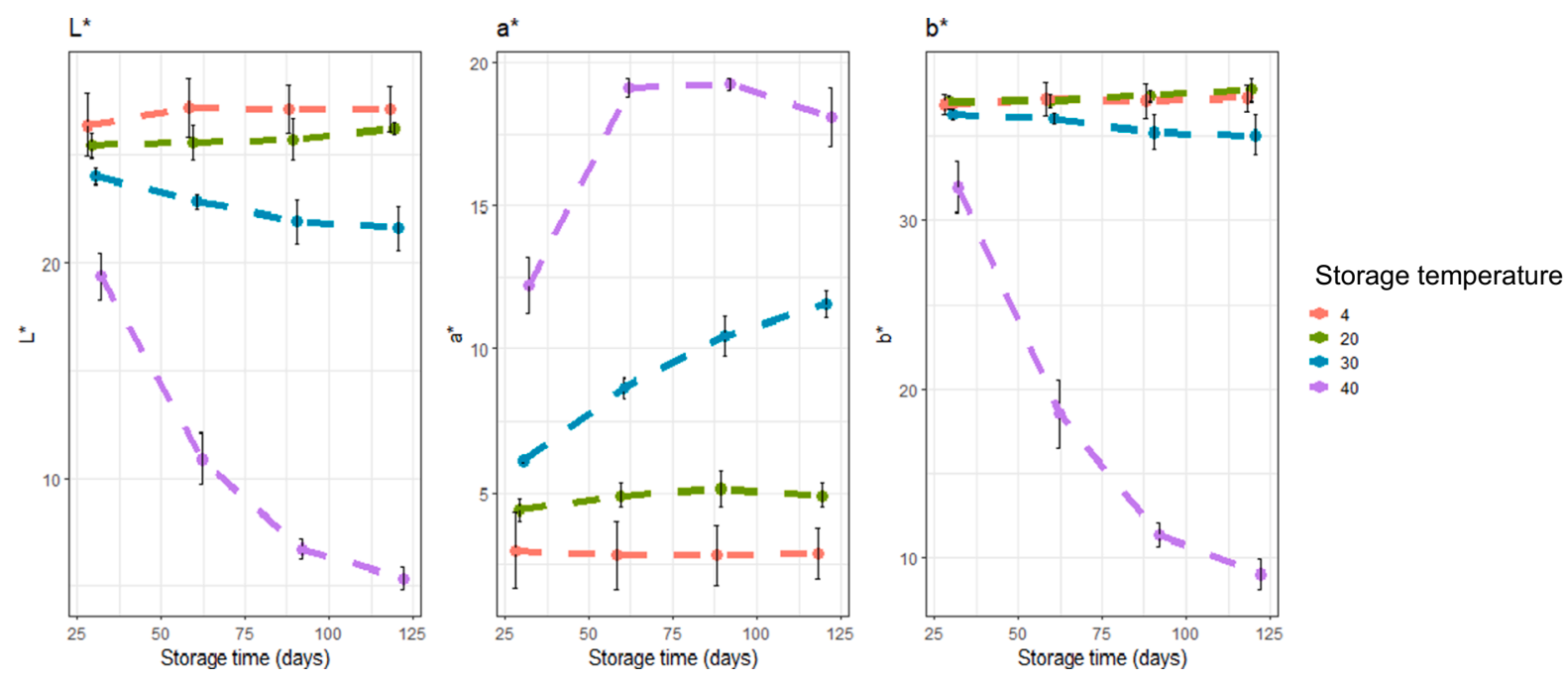

Fig. 3. Changes in the CIELab parameters $\mathrm{L}^{*}$, $\mathrm{a}^{*}$, and $\mathrm{b}^{*}$ in UHLM during storage at $4{ }^{\circ} \mathrm{C}, 20^{\circ} \mathrm{C}, 30^{\circ} \mathrm{C}, 40^{\circ} \mathrm{C}$. The data are the mean values of three measurements from three replicates of production $(n=9)$. 
MR in three stages disentangles the intricate network and rationalizes the significance of the compounds formed or degraded, but this does not entirely match the complexity of the MR pathways (Hodge, 1953). The resulting loading plot is reported in Fig. 4. The first two dimensions of the MFA accounted for $58.4 \%$ of the total variance (Dim1: $41.7 \%$; Dim2: $16.7 \%)$. Each dataset gave a different contribution to the two dimensions: for Dim1, color (41.79\%) and VOCs data (37.90\%) had a relevant impact, whereas only the free amino acids profile $(72.09 \%)$ was significant for the definition of Dim2. This confirms that the breakdown of milk protein in UHLM produced through "in batch" system is a secondary effect in comparison to the changes linked to the VOCs and color (Bottiroli, Troise, et al., 2020). Moreover, the effects of storage temperature overwhelmed the one of storage time on both dimensions, as already hypothesized looking at the PCA in Fig. 1. The increase in the storage temperature was the principal cause of UHLM modification for all the tested parameters, so utmost attention on temperature fluctuations at each step of the product life-cycle is requested. The different profiles of MR in the milk due to different storage temperature was nicely depicted on Dim1: most free amino acids, present at higher concentrations in UHLM kept at $4{ }^{\circ} \mathrm{C}$ for 120 days, gave a negative contribution to the dimension and were counterpoised to a positive contribution of the VOCs, whose maximum formation occurred at $40^{\circ} \mathrm{C}$. Thus, the route of MR towards advanced stages is modulated by the storage temperature which influence the rate at which specific VOCs (e. g. 2-methylbutanal, dimethyl disulfide, benzaldehyde) are formed from the pool of free amino acids generated upon "in batch" production. Other reaction pathways overlapped MR when the storage temperature was higher than the conventional $20{ }^{\circ} \mathrm{C}$. Indeed, products of Strecker degradation were positively correlated to 2-butanone ( $r>0.69$ ), 2-pentanone $(r>0.89)$, 2-heptanone $(r>0.50)$, 2-nonanone ( $r>0.78)$, 2undecanone $(r>0.83)$ and 2-tridecanone $(r>0.80)$ indicating a possible coordination of fatty acids oxidation and MR. All the Pearson coefficient calculated between Strecker degradation products and methyl ketones were statistically significant $(P \leq 0.05)$. Volatiles MRPs and methyl ketones were associated to milk browning represented by an increase of $a^{*}$ (red/green, $r>0.65$ ) and a simultaneous decrease of $L^{*}$ (lightness, $r>-0.76$ ) and $b^{*}$ (yellow/blue, $r>-0.76$ ). Even in this case, the correlations were statistically significant $(P \leq 0.05)$. MR and fat oxidation follow similar reaction pathways that can interact with each other and share common intermediates (Zamora \& Hidalgo, 2005), so a mutual participation to the milk browning is plausible. In our study, the relationship between MR and lipid oxidation emerged only when the UHLM was stored for 120 days at $30^{\circ} \mathrm{C}$ and, especially, $40{ }^{\circ} \mathrm{C}$. Therefore, as long as UHLM is maintained around room temperature throughout shelf-life, the two reactions are monitored without risks of color and flavor alteration. Contrarily, fluctuations towards higher storage temperature concomitantly trigger MR and lipid or fatty acids oxidation with the formation of a myriad of compounds potentially detrimental for the sensory quality of the product. In this frame, the MFA was demonstrated as a useful tool for mapping the chemical reaction underpinning the response of UHLM produced by "in batch" system to different storage temperature during shelf-life.

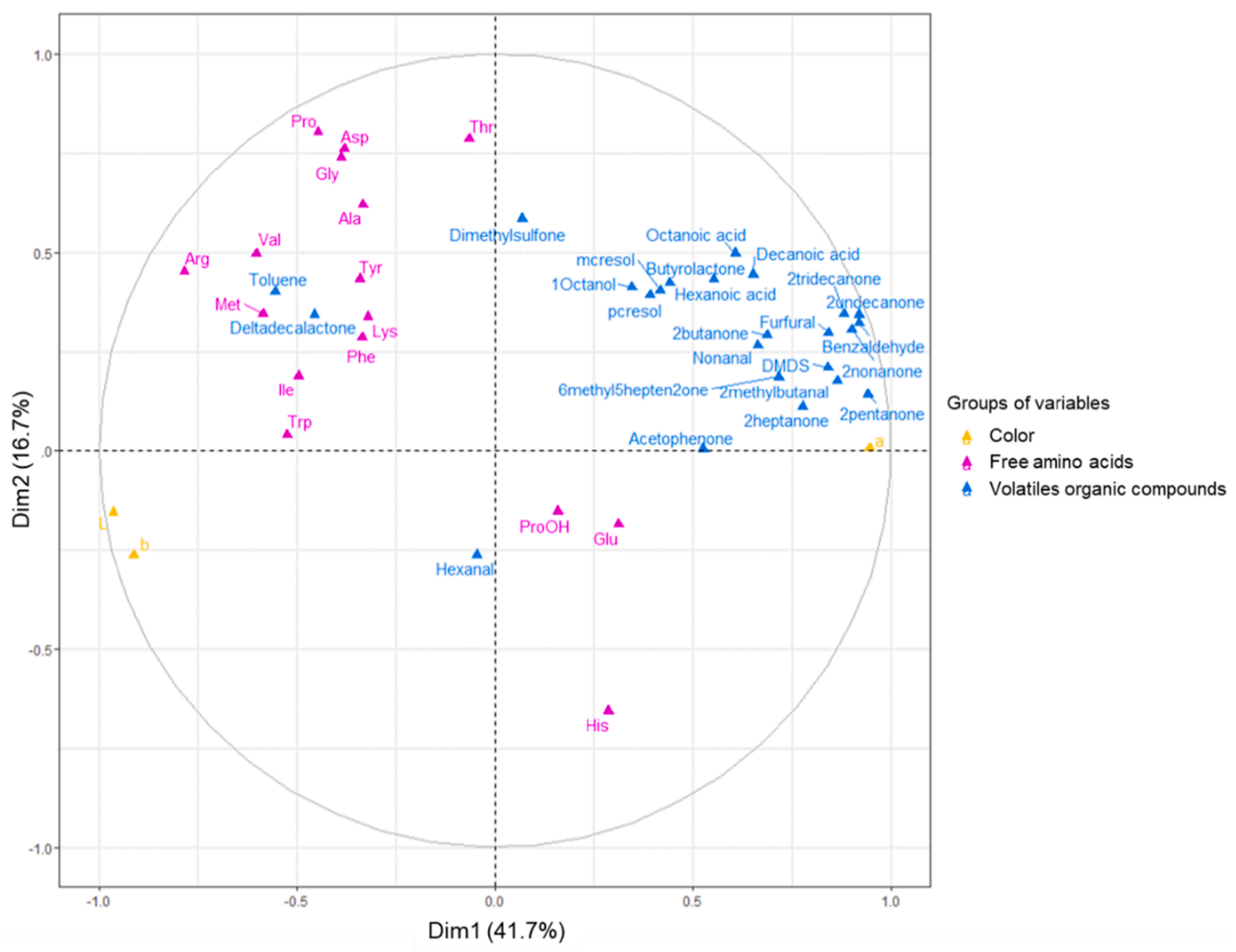

Fig. 4. Loading plot of the multiple factor analysis (MFA) model with Dim1 and Dim 2 explaining $41.7 \%$ and $16.7 \%$ of the total variance respectively. The analysis was performed on the mean values of the free amino acids (magenta), VOCs (blue), color (yellow) data obtained from the analysis of the UHLM samples stored at $4{ }^{\circ} \mathrm{C}, 20^{\circ} \mathrm{C}, 30^{\circ} \mathrm{C}, 40^{\circ} \mathrm{C}$ for 120 day (sampling every 30 days). (For interpretation of the references to color in this figure legend, the reader is referred to the web version of this article.) 


\section{Conclusions}

The severity of thermal treatment, the consequent array of reactions and the chemical nature of precursors render the design of shelf-life stable UHLM a challenge for dairy producers. The study of quality parameters cannot be confined in one single reaction, but a multi-faceted approach is required to depict a cause-effect relationship between the technology used and desired outcomes as prolonged shelf-life, and control of off-flavors formation and the milk color. We outlined how the control of temperature during storage is a crucial parameter to tune the formation of methyl-ketones and VOCs related to off-flavor formation in UHLM. Developing UHLM with shelf-life close to regular UHT milk would facilitate the distribution and minimize the financial losses of both producers and retailers (Nielsen et al., 2017). Furthermore, we introduced the possibility that lipid oxidation with formation of ketones, protein oxidation with the formation of methionine oxidation products and MR via Strecker degradation (2-methylbutanal and phenylacetaldehyde) can be characterized by interconnected reaction pathways with implications on color development. In this respect, ad hoc purification and mass spectrometry techniques can provide further evidence on the control of color and flavor development in dairy-based products and in particular to lactose-hydrolyzed milks.

\section{CRediT authorship contribution statement}

Riccardo Bottiroli: Investigation, Formal analysis, Writing - original draft, Visualization. Antonio Dario Troise: Writing - review \& editing. Eugenio Aprea: Conceptualization, Writing - review \& editing, Supervision. Vincenzo Fogliano: Conceptualization, Funding acquisition, Resources, Writing - review \& editing, Supervision. Flavia Gasperi: Conceptualization, Resources, Funding acquisition, Writing - review \& editing, Supervision. Paola Vitaglione: Resources, Funding acquisition, Writing - review \& editing, Supervision.

\section{Declaration of Competing Interest}

The authors declare that they have no known competing financial interests or personal relationships that could have appeared to influence the work reported in this paper.

\section{Acknowledgements}

The present study was financially supported by Wageningen University, Edmund Mach Foundation, and University of Naples "Federico II" as part of the Ph.D. project of Riccardo Bottiroli. The authors warmly thank Emanuela Betta for the technical support throughout the study.

\section{Appendix A. Supplementary material}

Supplementary data to this article can be found online at https://doi. org/10.1016/j.foodres.2021.110120.

\section{References}

Abernethy, G., \& Higgs, K. (2013). Rapid detection of economic adulterants in fresh milk by liquid chromatography-tandem mass spectrometry. Journal of Chromatography A, 1288, 10-20. https://doi.org/10.1016/j.chroma.2013.02.022.

Adhikari, K., Dooley, L. M., Chambers, E., IV, \& Bhumiratana, N. (2010). Sensory characteristics of commercial lactose-free milks manufactured in the United States. LWT - Food Science and Technology, 43(1), 113-118. https://doi.org/10.1016/j. lwt.2009.06.017.

Bimbo, F., Bonanno, A., Liu, X., \& Viscecchia, R. (2016). Hedonic analysis of the price of UHT-treated milk in Italy. Journal of Dairy Science, 99(2), 1095-1102. https://doi. org $/ 10.3168 /$ jds.2015-10018.

Bottiroli, R., Aprea, E., Betta, E., Fogliano, V., \& Gasperi, F. (2020). Application of headspace solid-phase micro-extraction gas chromatography for the assessment of the volatiles profiles of ultra-high temperature hydrolysed-lactose milk during production and storage. International Dairy Journal, 104715. https://doi.org/ 10.1016/j.idairyj.2020.104715.
Bottiroli, R., Pedrotti, M., Aprea, E., Biasioli, F., Fogliano, V., \& Gasperi, F. (2020). Application of PTR-TOF-MS for the quality assessment of lactose-free milk: Effect of storage time and employment of different lactase preparations. Journal of Mass Spectrometry, (February), 1-9. https://doi.org/10.1002/jms.4505.

Bottiroli, R., Troise, A. D., Aprea, E., Fogliano, V., Vitaglione, P., \& Gasperi, F. (2020). Chemical and sensory changes during shelf-life of UHT hydrolyzed-lactose milk produced by "in batch" system employing different commercial lactase preparations. Food Research International, 136(July), Article 109552. https://doi.org/10.1016/j. foodres.2020.109552.

Brands, C. M. J., \& Van Boekel, M. A. J. S. (2001). Reactions of monosaccharides during heating of sugar - Casein systems: Building of a reaction network model. Journal of Agricultural and Food Chemistry, 49(10), 4667-4675. https://doi.org/10.1021/ jf001430b.

Contarini, G., \& Povolo, M. (2002). Volatile fraction of milk: Comparison between, purge and trap and solid phase microextraction techniques. Journal of Agricultural and Food Chemistry, 50(25), 7350-7355. https://doi.org/10.1021/jf025713a.

Contarini, G., Povolo, M., Leardi, R., \& Toppino, P. M. (1997). Influence of heat treatment on the volatile compounds of milk. Retrieved from Journal of Agricultural and Food Chemistry, 45(3), 3171-3177 https://pubs.acs.org/sharingguidelines.

Cremer, D. R., Vollenbroeker, M., \& Eichner, K. (2000). Investigation of the formation of Strecker aldehydes from the reaction of Amadori rearrangement products with ofamino acids in low moisture model systems. European Food Research and Technology, 211(6), 400-403. https://doi.org/10.1007/s002170000196.

Dekker, P. J., Koenders, D., Bruins, M. J., et al.DSM Biotechnology Center, Alexander Fleminglaan 1, 2613 AX Delft, The Netherlands, DSM Food Specialties, Alexander Fleminglaan 1, 2613 AX Delft, The Netherlands, Nutrition Science \& Advocacy, DSM Nutritional Products, 4323 Kaiseraugst, Switzerland. (2019). Lactose-free dairy products: market developments, production, nutrition and health benefits. Nutrients, 11(3), 551. https://doi.org/10.3390/nu11030551.

Deeth, H. C., \& Lewis, M. J. (2017). High temperature processing of milk and milk products. John Wiley \& Sons. https://doi.org/10.1002/9781118460467.ch6.

Francis, L. L., Chambers, D. H., Kong, S. H., Milliken, G. A., Jeon, I. J., \& Schmidt, K. A. (2005). Serving temperature effects on milk flavor, milk aftertaste, and volatile compound quantification in nonfat and whole milk. Journal of Food Science, 70(7), s413-s418. Retrieved from www.ift.org.

Hannß, M., Hubbe, N., \& Henle, T. (2018). Acid-induced gelation of caseins glycated with lactose: Impact of maillard reaction-based glycoconjugation and protein crosslinking. Journal of Agricultural and Food Chemistry, 66(43), 11477-11485. https:// doi.org/10.1021/acs.jafc.8b04176.

Hodge, J. E. (1953). Dehydrated foods, chemistry of browning reactions in model systems. Journal of Agricultural and Food Chemistry, 1(15), 928-943. https://doi.org/ 10.1021/jf60015a004.

Hofmann, T., \& Schieberle, P. (2000). Formation of aroma-active Strecker-aldehydes by a direct oxidative degradation of Amadori compounds. Journal of Agricultural and Food Chemistry, 48(9), 4301-4305. https://doi.org/10.1021/jf000076e.

Jansson, T., Clausen, M. R., Sundekilde, U. K., Eggers, N., Nyegaard, S., Larsen, L. B., .. Bertram, H. C. (2014). Lactose-hydrolyzed milk is more prone to chemical changes during storage than conventional ultra-high-temperature (UHT) milk. Journal of Agricultural and Food Chemistry, 62(31), 7886-7896. https://doi.org/10.1021/ jf501671z.

Jansson, T., Rauh, V., Danielsen, B. P., Poojary, M. M., Waehrens, S. S., Bredie, W. L. P., .. Lund, M. N. (2017). Green tea polyphenols decrease strecker aldehydes and bind to proteins in lactose-hydrolyzed UHT Milk. Journal of Agricultural and Food Chemistry, 65(48), 10550-10561. https://doi.org/10.1021/acs.jafc.7b04137.

Jansson, T., Waehrens, S. S., Rauh, V., Danielsen, B. P., Sørensen, J., Bredie, W. L. P., .. Lund, M. N. (2019). Effect of green tea catechins on physical stability and sensory quality of lactose-reduced UHT milk during storage for one year. International Dairy Journal, 95, 25-34. https://doi.org/10.1016/j.idairyj.2019.03.007.

Jensen, S., Jansson, T., Eggers, N., Clausen, M. R., Larsen, L. B., Jensen, H. B., Bertram, H. C. (2015). Storage-induced changes in the sensory characteristics and volatiles of conventional and lactose-hydrolyzed UHT processed milk. European Food Research and Technology, 240(6), 1247-1257. https://doi.org/10.1007/s00217-0152427-9.

Messia, M. C., Candigliota, T., \& Marconi, E. (2007). Assessment of quality and technological characterization of lactose-hydrolyzed milk. Food Chemistry, 104(3), 910-917. https://doi.org/10.1016/j.foodchem.2006.12.045.

Milkovska-Stamenova, S., \& Hoffmann, R. (2017). Influence of storage and heating on protein glycation levels of processed lactose-free and regular bovine milk products. Food Chemistry, 221, 489-495. https://doi.org/10.1016/j.foodchem.2016.10.092.

Morales, F. J., \& Van Boekel, M. A. J. S. (1998). A study on advanced Maillard reaction in heated casein/sugar solutions: Colour formation. International Dairy Journal, 8 (10-11), 907-915. https://doi.org/10.1016/S0958-6946(99)00014-X.

Naranjo, G. B., Gonzales, A. S. P., Leiva, G. E., \& Malec, L. S. (2013). The kinetics of Maillard reaction in lactose-hydrolysed milk powder and related systems containing carbohydrate mixtures. Food Chemistry, 141(4), 3790-3795. https://doi.org/ 10.1016/j.foodchem.2013.06.093.

Nielsen, S. D., Jansson, T., Le, T. T., Jensen, S., Eggers, N., Rauh, V., ... Larsen, L. B. (2017). Correlation between sensory properties and peptides derived from hydrolysed-lactose UHT milk during storage. International Dairy Journal, 68, 23-31. https://doi.org/10.1016/j.idairyj.2016.12.013.

Nielsen, S. D., Zhao, D., Le, T. T., Rauh, V., Sørensen, J., Andersen, H. J., \& Larsen, L. B. (2018). Proteolytic side-activity of lactase preparations. International Dairy Journal, 78, 159-168. https://doi.org/10.1016/j.idairyj.2017.12.001.

O'Mahony, J. A., Drapala, K. P., Mulcahy, E. M., \& Mulvihill, D. M. (2017). Controlled glycation of milk proteins and peptides: Functional properties. International Dairy Journal, 67, 16-34. https://doi.org/10.1016/j.idairyj.2016.09.012. 
Perkins, M. L., Elliott, A. J., D'Arcy, B. R., \& Deeth, H. C. (2005). Stale flavour volatiles in Australian commercial UHT milk during storage. Australian Journal of Dairy Technology, 60(3), 231-237.

Rizzi, G. P. (1997). Chemical structure of colored Maillard reaction products. Food Reviews International, 13(1), 1-28. https://doi.org/10.1080/87559129709541096.

Sunds, A. V., Rauh, V. M., Sørensen, J., \& Larsen, L. B. (2018). Maillard reaction progress in UHT milk during storage at different temperature levels and cycles. International Dairy Journal. https://doi.org/10.1016/j.idairyj.2017.08.008.

Tossavainen, O., \& Kallioinen, H. (2007). Proteolytic changes in lactose hydrolysed UHT milks during storage. Retrieved from Milchwissenschaft, 62(4), 410-415 http://cat. inist.fr/?aModele=afficheN\&cpsidt $=19123002$.

Tossavainen, O., \& Kallioinen, H. (2008). Effect of lactose hydrolysis on furosine and available lysine in UHT skim milk. Milchwissenschaft, 63(1), 22-26.

Troise, A. D., Bandini, E., De Donno, R., Meijer, G., Trezzi, M., \& Fogliano, V. (2016). The quality of low lactose milk is affected by the side proteolytic activity of the lactase used in the production process. Food Research International, 89, 514-525. https://doi. org/10.1016/j.foodres.2016.08.021.

Troise, A. D., Wiltafsky, M., Fogliano, V., \& Vitaglione, P. (2018). The quantification of free Amadori compounds and amino acids allows to model the bound Maillard reaction products formation in soybean products. Food Chemistry, 247, 29-38. https://doi.org/10.1016/J.FOODCHEM.2017.12.019.

Valero, E., Villamiel, M., Miralles, B., Sanz, J., \& Martínez-Castro, I. (2001). Changes in flavour and volatile components during storage of whole and skimmed UHT milk. Food Chemistry, 72(1), 51-58. https://doi.org/10.1016/S0308-8146(00)00203-X.

van Boekel, M. A. J. S. (1998). Effect of heating on Maillard reactions in milk. Food Chemistry, 62(4), 403-414.

van Boekel, M. A. J. S. (2006). Formation of flavour compounds in the Maillard reaction. Biotechnology Advances, 24(2), 230-233. https://doi.org/10.1016/J. BIOTECHADV.2005.11.004.

Vazquez-Landaverde, P. A., Velazquez, G., Torres, J. A., \& Qian, M. C. (2005). Quantitative determination of thermally derived off-flavor compounds in milk using solid-phase microextraction and gas chromatography. Journal of Dairy Science, 88 (11), 3764-3772. https://doi.org/10.3168/jds.S0022-0302(05)73062-9.

Zabbia, A., Buys, E. M., \& de Kock, H. L. (2012). Undesirable Sulphur and carbonyl flavor compounds in UHT milk: A review. Critical Reviews in Food Science and Nutrition. https://doi.org/10.1080/10408398.2010.487166.

Zamora, R., \& Hidalgo, F. J. (2005). Coordinate contribution of lipid oxidation and Maillard reaction to the nonenzymatic food browning. Critical Reviews in Food Science and Nutrition, 45(1), 49-59. https://doi.org/10.1080/10408690590900117. 